\title{
On the reducing powers of arsenious acid
}

\section{G. Bonnet}

To cite this article: G. Bonnet (1836) On the reducing powers of arsenious acid, Philosophical Magazine Series 3, 9:53, 230-232, DOI: 10.1080/14786443608636485

To link to this article: http://dx.doi.org/10.1080/14786443608636485

册 Published online: 01 Jun 2009.

Submit your article to this journal

Џ Article views: 3

Q View related articles $₫$ 
ten days numerous rhomboidal crystals, resembling those of the cave: in order to ascertain whether light had any influence in the process, he tried it again in a dark cellar, and produced similar crystals in six days, with one fourth of the voltaic power. He had repeated the experiments a hundred times, and always with the same results. He was fully convinced that it was possible to make even diamonds, and that at no distant period every kind of mineral would be formed by the ingenuity of man. By a variation of his experiments he had obtained green and blue carbonate of copper, phosphate of soda, and 20 or 30 other specimens.

Mr. Crosse having also observed in a cavern in the Quantock Hills near his residence that the part of it which consisted of slate was studded with crystals of arragonite, while the limestone part was covered with crystals of ordinary carbonate of lime, or calcareous spar, subjected portions of each of these substances in water tolongcontinued galvanic action, and obtained from the

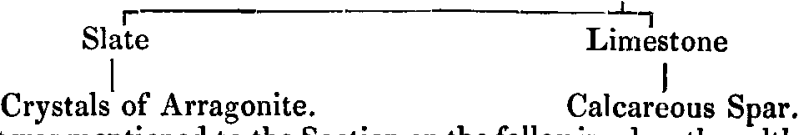

It was mentioned to the Section on the following day, that although no doubt could be entertained of the independence and originality of Mr. Crosse's experiments, yet that he had been anticipated, in the artificial production of many of the crystallized bodies which he had formed, by M. Becquerel, and some other French chemists.

\section{AURORA BOREALIS OBSERVED IN THE ISLE OF WIGHT, ON AUGUST 10TH.}

An aurora borealis was observed at Ryde, Isle of Wight, on the night of Wednesday the 10th instant (August), which for its intensity, its occurrence so far south, and at such a time of the year, is worth recording. It was first observed about half-past eleven o'clock. There was the usual dark band upon the horizon under the magnetic north, and to some distance right and left of that point : at intervals of time the space above this became luminous, like a glow of twilight, and this broke out into columns, nearly upright, but inclining above to the east, and, as far as could be judged by the eye, parallel to each other, and not convergent to the zenith or any other point in the heavens. They were gradually transferred by a slow motion from west to east, and generally ended by assuming a fine red colour. The appearance continued for an hour or more, but about one o'clock all had resumed the ordinary state. The stars were out, twinkling very much, and falling stars were observed frequently on that and the three or four preceding evenings. M. F.

\section{ON THE REDUCING POWERS OF ARSENIOUS ACID.} BY G. BONNET, ORNSHAGEN, POMERANIA.

When arsenite of copper is put into a solution of caustic potash or soda the colour of the mix ture turns to a yellowish brown. This effect takes place at ordinary temperatures, quicker or slower according to the strength of the alkali; upon application of heat the process is hastened and perfected. The same effect also occurs 
when arsenite of potash or soda is mixed with a solution of any salt of copper, and a caustic alkali is added to it. It also takes place on mixing arsenite of potash or soda with hydrated oxide of copper, and then adding a caustic alkali; the change is very slow with heated oxide of copper. Upon examination of the precipitate after washing the following action takes place.

Diluted sulphuric acid is coloured blue, and metallic copper is left; muriatic acid added in a small quantity changes the precipitate into a white powder, a larger quantity gives a brown solution; from which it follows that the precipitate is a suboxide of copper; this is confirmed by the experiments which follow. The reduction of the oxide of copper can only be attributed to the effect of the arsenious acid, which it is to be observed is converted into arsenic acid. 100 parts of arsenious acid, taking 16.1 parts of ox ygen for its conversion into arsenic acid will therefore convert $159 \cdot 6$ of oxide copper into suboxide. In order to ascertain whether the reduction of the oxide of copper by the addition of the ingredients in this proportion would also result, as well as by the employment of arsenite of copper in which a larger quantity of arsenious acid was present, the following experiments were made :

1.6 gramme oxide of copper were dissolved in very dilute sulphuric, and $1 \mathrm{grm}$. of arsenious acid was dissolved in a solution of 10 grms. of caustic soda of specific gravity 1.20 ; the solutions were mixed together cold, and 20 grms. caustic alkali were added; the mixture was placed in a warm situation and often stirred; the colour soon changed and the precipitate completely formed. The solution was poured off, and the suboxide copper was washed with warm water and separated.

The solution was neutralized by nitric acid; sulphate of copper gave a blue precipitate, and nitrate of silver a reddish brown precipitate, indicating the presence of arsenic acid.

The washed precipitate mixed with boiled water acidulated by sulphuric acid changed immediately to brown flakes of metallic copper; the supernatant liquid was poured off, and the copper well washed with boiling water, collected and weighed; it weighed 0.62 gram.

One half of 1.6 gramme of oxide of copper will give 0.638 metallic copper. The result of the foregoing experiment agrees nearly with this; it may be considered therefore that all the oxide of copper is reduced by arsenious acid to the state of suboxide. If this experiment were repeated by taking double the quantity of arsenious acid the same result would take place, and the oxide of copper would be only reduced to the state of suboxide.

When caustic ammonia is used, the oxide of copper is only partially converted into suboxide. The solution remains perceptibly blue, and only becomes colourless upon the addition of a caustic alkali. If the blue ammoniacal solution is supersaturated by sulphuric acid, metallic copper is precipitated.

The carbonated alkalies occasion no perceptible reduction of oxide of copper, which is also the case with caustic lime.

Upon considering the reducing power of arsenious acid on oxide 
of copper, it is probable that oxygen may be separated from other metallic oxides; particularly in the case of the metallic acids which easily part with their oxygen. Several trials on metallic oxides gave negative results, but the idea was confirmed with regard to metallic acids.

Manganesiate of potash was dissolved in water, a caustic alkali, and then arsenite of soda were added; upon mixing, the green colour was restored, a dark brown precipitate fell, which was oxide of manganese.

Chromate of potash was dissolved, caustic alkali and arsenite of soda added, the solution on warming became green. In this case no oxide of chrome fell. The arsenious acid prevented the precipitation of the oxide of chrome by means of the alkali, which is evident by the following experiment.

Hydrated oxide of chrome was dissolved in muriatic acid, to which was added a solution of arsenite of potash: caustic alkali did not give the least trace of oxide of chrome. When to the solution of oxide of chrome in muriatic acid, arsenite of ammonia, and then ammonia, were added, no precipitate took place. It is to be remarked that arsenious acid has also a reducing power over other acids, for example, on molybdic and tungstic acid, but for want of these acids I was unable to make the necessary experiments.Poggendorff's Annals, 1836, No. 2.

ON THE COMPOSITION OF PLAGIONITE. BY RUDERNATSCH.

This mineral has been analysed by Professor H. Rose, who found it to consist of

Lead. ........4 40.52

Antimiony ..... 37.94

Sulphur...... 21:53

and has given the formula of $4 \mathrm{~Pb} \mathrm{~S}+3 \mathrm{Sb} \mathrm{S}^{3}$.

As this combination of sulphur in sulphuret of antimony is in a very uncommon proportion to the sulphuret of lead, namely as 9 to 4 , and as Berzelius, in his Jahresbericht, has thrown some doubt on the existence of such a compound, which he considers likely to be a mixture of the two, Mr. Rudernatsch was induced to repeat the examination of some very distinct and well-defined crystals : he followed the same mode of analysis as Professor Rose, which gave the following results :

$$
\begin{aligned}
& \text { Lead ... . . . . . . 40.98 } \\
& \text { Antimony..... 37.53 } \\
& \text { Sulphur. . . . . 21.49_-100 }
\end{aligned}
$$

In a second analysis, which was only to determine the quantity of lead, he found 40.81 per cent.

It therefore appears, by these analyses, that plagionite is a peculiar chemical combination.-Poggendorff's Annals, 1836, No. 4.

ON SOME TRIPLE COMBINATIONS OF CHLORIDE OF OSMIUM IRIDIUM AND PLATINUM WITH CHLORIDE OF POTASSIUM AND MURIATE OF AMMONIA. BY R. HERMANN OF MOSCOW. 1.-Triple Salt of Chloride of Osmium and Chloride of Iridium with Chloride of Potassium. - When the native mixture of iridium 